\title{
SALAS Y ALCOBAS EN SAN CRISTÓBAL DE LA HABANA. SIGLOS XVI Y XVII
}

LIVING ROOMS AND BEDROOMS IN HAVANA, $1^{\text {th }}$ AND $17^{\text {th }}$ CENTURIES

\author{
Rosalía Oliva Suárez* \\ Gabinete de Arqueología \\ Oficina del Historiador de La Habana
}

\section{Resumen}

El artículo es un acercamiento al mobiliario doméstico de dos espacios de la casa: la sala y la alcoba. A partir de fuentes de archivo, iconográficas y bibliografía se hace una reconstrucción de cómo eran ambas estancias en las viviendas habaneras en los dos primeros siglos de la Villa de San Cristóbal de La Habana. Interpretaciones de la forma de habitar de vecinos y residentes en una de las ciudades portuarias más importantes en los territorios españoles de ultramar.

Palabras clave: mobiliario doméstico, dormitorio, espacios domésticos, salas, La Habana.

Summary: This article is an approach to the domestic furniture of two spaces in the house: the living room and the bedroom. Based on archival, iconographic, and bibliographic sources, a reconstruction is made of what both rooms were like in Havana houses in the first two centuries of the Villa de San Cristóbal de La Habana. It provides interpretations on the way of living of neighbours and residents in one of the most important port cities in the Spanish overseas territories.

Keywords: domestic furniture, bedroom, domestic areas, living room, Havana

San Cristóbal de La Habana fue la séptima villa fundada por los españoles en la isla de Cuba. Andariega en sus inicios, se asentó definitivamente en el Puerto de Carenas ${ }^{1}$ en 1519, área que actualmente se conoce como el Centro Histórico de La Habana Vieja. No fue hasta mediados del siglo XVI, cuando se inicia la conquista de los territorios de ultramar que la Villa, declarada ciudad en 1592, se convierte en uno de los puertos más importantes de las Indias Occidentales, Llave del Nuevo Mundo.

Reconocidos investigadores cubanos, entre los que se encuentran, Anita Arroyo $^{2}$, Emilio Roig ${ }^{3}$, Leví Marrero y Lilia Martín Brito ${ }^{5}$, afirmaron que entre los siglos XVI y XVII ocurrieron importantes cambios en lo económico, lo social y lo político en la Isla, sin embargo, en las casas de la urbe habanera 
el mobiliario no sufrió grandes transformaciones, de forma general era sencillo y funcional, independientemente del rango de sus propietarios.

Los muebles fueron un grupo de objetos que tanto mujeres como hombres ingresaban al matrimonio. Es un rubro importante y presente en los testamentos, en las dotes y en otros tipos de escrituras notariales. En ellas, se detallan minuciosamente los materiales con que estaban construidos y los precios en que fueron valorados. Ejemplos son las camas y las sillas, se definen los colores de la tapicería, la madera y las medidas del moblaje. En relación con las prendas de vestir, se relata las telas con que estaban confeccionadas, los adornos y hasta si eran de uso o no. A pesar de que puede encontrarse un alto nivel de detalles sobre la hechura de los mismos, incluso el nombre del artesano que lo fabricó 6 o si fue comprado en otra ciudad, sin embargo, no se especifica en qué sitio de la vivienda fueron emplazados. Estos datos son significativos a la hora de estudiar los espacios domésticos y la funcionalidad de cada estancia, por lo que se hace necesario complementar la información que aportan los protocolos con fuentes tradicionales orales, iconográficas, arqueológicas y artes decorativas, para hacer interpretaciones más complejas de cómo fue el habitar dentro de las casas en el período colonial cubano. ${ }^{7}$

En el contexto de San Cristóbal de La Habana de los siglos XVI y XVII se ha podido constatar que la arquitectura doméstica era sencilla. ${ }^{8}$ Salvo en los casos de personajes distinguidos de la ciudad, la mayoría de las viviendas se componían de dos o tres habitaciones: una sala, uno o dos dormitorios y la cocina separada de la estructura habitacional; la cual se encontraba, la mayoría de las veces, al fondo del solar junto con los dormitorios de la servidumbre y otras áreas de servicios. ${ }^{9}$

$\mathrm{Al}$ compararse las dimensiones de las viviendas con las actividades que se efectuaban por los que la habitaban y sus invitados, se ha podido demostrar que las residencias habaneras se caracterizaron por la multifuncionalidad de los espacios. La sala podía ser de día: el taller del artesano, una fonda en los seis meses en que la Flota se encontraba en el puerto; o el sitio donde los propietarios pasaban la mayor parte del día recibiendo visitas o lugar de reunión. De noche, a los anteriores usos, se le agrega el del dormitorio, salón de fiesta, tertulias y otras actividades litúrgicas. ${ }^{10}$ Por otra parte, las alcobas eran habitaciones no solo para dormir, constituyeron áreas donde las mujeres de la casa se reunían, se cuidaba a los enfermos, y hasta constituyeron espacios de aseo. ${ }^{11}$

Al profundizar en los estudios sobre los muebles y sus usos en el hábito doméstico (alcobas y salas) en los dos primeros siglos de San Cristóbal de La Habana, cambiará la perspectiva de la imagen que se describe en las palabras de Hernando de la Parra, criado del gobernador Juan Maldonado, quien en 1598 expresaba: "Los muebles consisten en bancos y asientos de cedro o caoba sin respaldar, con cuatro pies que forran en lona o en cueros, que por lo regular es el lecho de la gente pobre..." 12 . La historiografía cubana ha interpretado como que el mobiliario doméstico habanero era pobre, rústico y sencillo sin observar la variedad dentro los mismos y sus funciones. Y es que, al analizar el menaje doméstico, no se pueden ver estos solo como objetos inanimados, sino que al observar los más mínimos cambios en su apariencia 
y hechura contribuyen a mostrar el desarrollo de las relaciones sociales que se establecieron a partir de sus usos. Los muebles no han estado divorciados de la capacidad de actuar de las personas y del poder comunicativo de las palabras. Propiedades (incluido el número de esclavos), muebles, vestidos, joyas, además de su función utilitaria, reflejan el estamento social, manifiestan el estilo de vida, los gustos, los valores y las personalidades de los dueños de la casa.

Las alcobas y las salas fueron dos estancias importantes en la vida cotidiana, a pesar de ello, han sido poco estudiadas, el objetivo de este trabajo es profundizar en estas dos habitaciones desde la perspectiva del mobiliario que se emplazaron en los mismos. ${ }^{13}$

\section{La Sala: La habitación más importante de la casa}

Las salas eran ubicadas en el frente de la casa, con acceso a la calle y al patio interior, la distinguió la mejor decoración y una variedad de muebles como mesas, bancos, sillas y taburetes. El elevado número de asientos en estos espacios pudieron indicar, no solo que se realizaran en ellos reuniones y/o tertulias y otras actividades sociales, sino también el de convertirse, por temporadas, en tabernas, pulperías y otros comercios.

Eran tantas las casas que a mediados del siglo XVI se convertían en tabernas o espacios de alquiler, que el Cabildo se vio en la necesidad de poner disciplina sobre el peso de la carne de cerdo, el vino y demás alimentos que se comercializaran en estos establecimientos temporales.

Ytem que las tales personas que dieren de comer sean obligadas a dar agua a los que comieren la que les bastare e mesa e manteles linpios de valde sin llevar por ello interese algund.

Ytem que si alguna persona quisiere dormir en las tales casas de trato que si le dieren una hamaca lleven por cada noche un rreal e sino le dieren hamaca ni otra cama medio Real. ${ }^{14}$

En 1562 según decía el Gobernador Mazariegos, la Habana era una villa de pocos vecinos y pobres, los cuales se sustentaban alquilando sus casas y vendiendo alimentos para avituallar los navíos que llegaban al puerto. ${ }^{15}$ Dicho gobernador llegó a contabilizar 40 tabernas. Estas referencias como tantas otras sugieren que los propietarios contaban con mesas, sillas, hamacas y otros muebles para ser utilizados por los forasteros y que, por las dimensiones de las casas, las salas fueron los espacios más adecuados para ofrecer estos tipos de servicios.

Las sillas, sillones ${ }^{16}$ y taburetes no solo producían un efecto físico como servir de asiento a las personas, sino tenían a su vez un significado de una auténtica jerarquía familiar y social. ${ }^{17} \mathrm{Su}$ valor simbólico es reflejado en los documentos de época en la manera en que fueron tasados. En la carta de recibo de dote que firmara el 7 de febrero de 1585, el vecino Andrés de Lebrija, declaraba que su esposa había traído al matrimonio además de la vivienda un grupo considerable de muebles. Encabezando la lista “... siete sillas a un ducado cada una...", luego sin hacer más referencia de otro mueble para este uso se describían mesas, cojines, cajas y demás ajuar de cama. ${ }^{18}$ 
A pesar de que en algunos documentos se mencionan de forma indistinta los taburetes como sillas y viceversa, no pudiendo definirse como era su aspecto, existen otros, que además de indicar con qué maderas fueron hechos (cedro, granadillo o caoba), declaran no solo la diferencia, sino también el valor de unos sobre otros. En el testamento del vecino de La Habana Cristóbal de Casilla que se firmara en 1650, se inventariaba:

Por el valor de sus casas que fueron su morada, que se tasaron por el maestro mayor Joseph Hidalgo en 28000 reales (...) 48 reales por un bufete de caoba; 168 reales por 7 sillas de caoba viejas; 100 reales por ua colcha de china usada; 112 reales por 7 taburetes viejos; 80 reales por un tapete y cojin viejo; y estas partidas suman y montan conforme a su tasación 56168 reales (...). ${ }^{19}$

En el fragmento que se ha extraído del inventario notarial donde se hallan los muebles para sentarse no sólo se aprecia un número semejante de sillas y taburetes, sino que a pesar de reconocerse por el tasador que eran de uso, "viejas", las primeras eran tasadas en un mayor valor y se definía con qué madera eran hechas: de caoba. La caoba es una madera oscura y dura considerada preciosa por su calidad. Los muebles hechos de esta madera eran valorados sobre los de cedro y el granadillo. Esto se debía no sólo porque la caoba se encuentra en menor número, sino también a que no todos los artesanos sabían trabajarla.

El uso de los taburetes (fig. 1) fue generalizado independientemente del origen de sus propietarios, la diferencia consistía en la cantidad y calidad de la hechura de los mismos. Así lo demuestra en la carta de dote firmada en 1650 por el vecino acaudalado Alonso Soria el cual disponía de 6336 reales. En dicha escritura se hallaban tres sillas y tres taburetes nuevos con tachuelos dorados tasado todo en 246 reales. ${ }^{20}$ Otro ejemplo de elaborados bordados y clavazón en lienzo fueron las seis sillas y los seis taburetes que se hallaban en la dote de la señorita Andrea de la Torre, fechada en 1689, valorados en su totalidad en 40 pesos. ${ }^{21}$

En las salas de las viviendas de los vecinos más acaudalados, se colocaron además de las sillas y los taburetes, algún tipo de estrado; el cual era una especie de tarima de madera con alfombras, cojines y almohadas para sentarse; donde las mujeres de la casa se dedicaban a tareas de costura y a recibir visitas de su mismo nivel social. Citando a la estudiosa colombiana María Luisa Lobo Montalvo, dicho mueble constituyó, en varias regiones de Latinoamérica, "...la pieza más importante de la vida familiar, ya que servía de lugar de trabajo y en las noches, de cama". ${ }^{22}$ Por otra parte, la historiadora española Gloria Franco afirma que este tipo de mueble presupone que era una parte de la sala principal donde los hombres no solían acercarse y que pervivió hasta finales del siglo XVIII, desapareciendo cuando el salón se convierte en un espacio intersexual, donde las relaciones entre hombres y mujeres eran más abiertas y libres. ${ }^{23}$

En las escrituras notariales estudiadas no se ha encontrado la palabra estrado, lo que no significa que no se hayan utilizado en La Habana. Quizás el término no fuese manejado por los escribanos asentados en la ciudad y si por ejemplo el de tarima, que tenía el mismo fin, dividir espacios en altura. 
Una tarima grande y otra pequeña, junto con mantas y cojines le fueron otorgadas en dote a la huérfana Micaela Calvo en el año de 1687.24

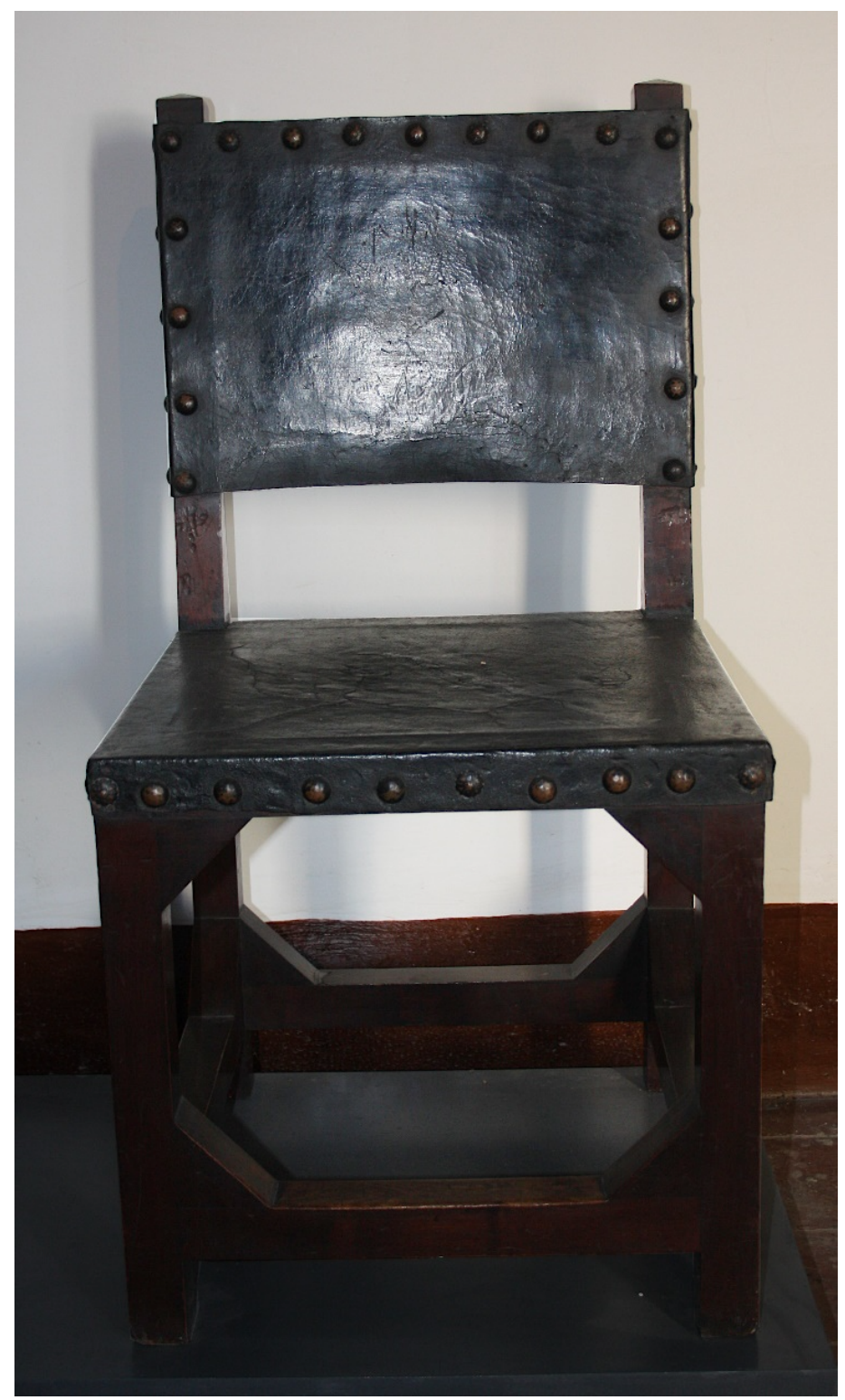

Fig. 1. Taburete de caoba y vaqueta del siglo XVII, Museo de Arte Colonial, Oficina del Historiador de La Habana, fotografía de Rodrigo Ponce, La Habana 2020

La presencia de mantas, alfombras y cojines en el ajuar doméstico a la usanza de las viviendas andaluzas, se aprecia en el gran número de textiles que compraban los vecinos cuando llegaba la Flota. Damasco, ruán, carmesí, seda carmesí, bocací y tafetán eran importados desde España y otros puertos como el de Veracruz, para elaborar este tipo de artículos que eran colocados sobre bancos, entablados o simplemente en el suelo para sentarse y otorgar a los espacios confort y distinción. ${ }^{25}$ En agosto de 1590 se desposaban ante la Santa Iglesia, la señorita Melchora de Salazar y Juan Soto, ambos 
representantes de las familias más distinguidas de la Villa de San Cristóbal de La Habana. Entre los bienes aportados por la doncella se encontraban tres cojines con bordados valorados en quince ducados cada uno, que en reales eran 165 reales y una alfombra en catorce ducados (154 reales). ${ }^{26}$

El uso de alfombras y cojines no fue privativo de las viviendas, también fue costumbre que las damas los llevasen a las iglesias a la hora de las misas y otros cultos, trayendo el reproche de algunas autoridades eclesiásticas, como la del Fray Antonio Díaz de Salcedo, franciscano mayor de colonia que dictó su prohibición en 1597. A partir de ese entonces los esclavos llevaban para sus amas pequeñas sillas, bancos y otros tipos de asientos pequeños hermosamente decorados con nácar y otros materiales. ${ }^{27}$

En las habitaciones de importancia, como la sala principal y los aposentos no faltó algún tipo de espejo vistiendo las paredes. Como enuncia la investigadora argentina Cecilia Edith Moreyra, el uso de los espejos dentro de las casas se remitía a una moda de los palacios europeos:

Estas piezas, símbolo por excelencia de la vanidad humana, y tal vez utilizados para dar más luz a las habitaciones, eran propias de los estamentos más acaudalados, por lo que también se convirtieron en distintivos sociales. No todos tenían el privilegio de conocer el propio rostro o ver reflejado su cuerpo entero. ${ }^{28}$

La presencia cada vez mayor de espejos en los espacios domésticos habaneros se debe a un aumento del interés personal por la higiene y la belleza en la población femenina, que trajo como consecuencia la proliferación del comercio de artículos de lujo entre los que se incluían los mismos. El comercio de este tipo de artículos no sólo fue privativo de La Habana, así lo demuestra la relación de la mercadería que fue traslada desde esta ciudad, en 1579, por la compañía concertada entre los comerciantes Gaspar de Ávila y Rodrigo Ortiz donde se hallaban “... seis espejos grandes de crital, valorados en siete ducados y dos espejos chequitos, en diez y ocho rreales". ${ }^{29}$

Además de los espejos, algunos cuadros con motivos religiosos embellecieron las paredes de las viviendas. Entre los bienes dotales de la hija del alférez Blas Barrieto, otorgados en 1690, se incluían tres cuadros con imágenes religiosas medianos, de diferentes hechuras, valorados en quince pesos y tres láminas en tres pesos. ${ }^{30}$ En el testamento del vecino Pedro Recio Borroto, con fecha del 2 de mayo de 1699, se declaraba que entre sus bienes se hallaban un cuadro de la Pasión de Cristo tasado en 6 pesos, dos en 11 pesos, un cuadro en 6 pesos y dos más pequeños en 2 pesos cada uno. ${ }^{31}$

Este tipo de pintura es el reflejo del marcado carácter religioso de la población en La Habana colonial. La presencia de imágenes religiosas en las casas enfatiza el carácter de talismán, convirtiéndose en una coraza protectora contra lo maligno, ${ }^{32}$ contra lo desconocido e incluso como protección ante la presencia de otras religiones en la ciudad, como las de los afrodescendiente y las de origen aborigen. La imposición de la religión católica hizo que la materialidad de los objetos religiosos fuese a imagen y semejanza de lo que ocurría en España.

Otro grupo de muebles muy comunes en las viviendas y que no solo eran privativos de las salas, también se emplazaron en alcobas y cocinas fueron las cajas y baúles (fig. 2). Estos eran de madera, en su mayoría de cedro, y podían 
tener una o más cerraduras. En ellos se almacenaba ropa de cama, vestuario de uso, herramientas, libros imágenes religiosas y documentos personales, entre otros objetos. Si estos contenían cerradura y llave, su valor era mayor. El deseo de guardar con llave tiene que ver en buena parte con esa aspiración de todo individuo de tener privacidad, las ansias de resguardar sus bienes ante la mirada de otros familiares y sobre todo de la servidumbre.

En el año de 1593, en el inventario que se realizara tras el fallecimiento del Capitán Francisco de Moncayo, veedor y contador de las galeras de la isla de Cuba, se encontraba entre otros bienes: una caja de cedro que servía de despensa, un cofre grande que se declaraba que era viejo; además, otras dos cajas de cedro y dos baúles con cubiertas de cuero. ${ }^{33}$

Pasado casi cien años, el vecino prominente Pedro Hernández, otorgó como dote a su hija, en 1687, una caja de cedro mediana con cerradura y llave valorada en 8 pesos. ${ }^{34}$ Por esta misma época en la carta de última voluntad del residente en La Habana, Alonso de Jea, natural de la villa de Mila, en el Reino de Murcia:

(...) tiene por vienes viejos, una caja pequeña de cedro, y en ella ropa de su vestir; 3 (...) de plata y una franquicis con sus (...) y 2 pequeñas; 3 pipas vacias; 3 cazuelas, una fameja de sal, 6 botijas perulesa y otros trastes que en su tienda aparecerían. ${ }^{35}$

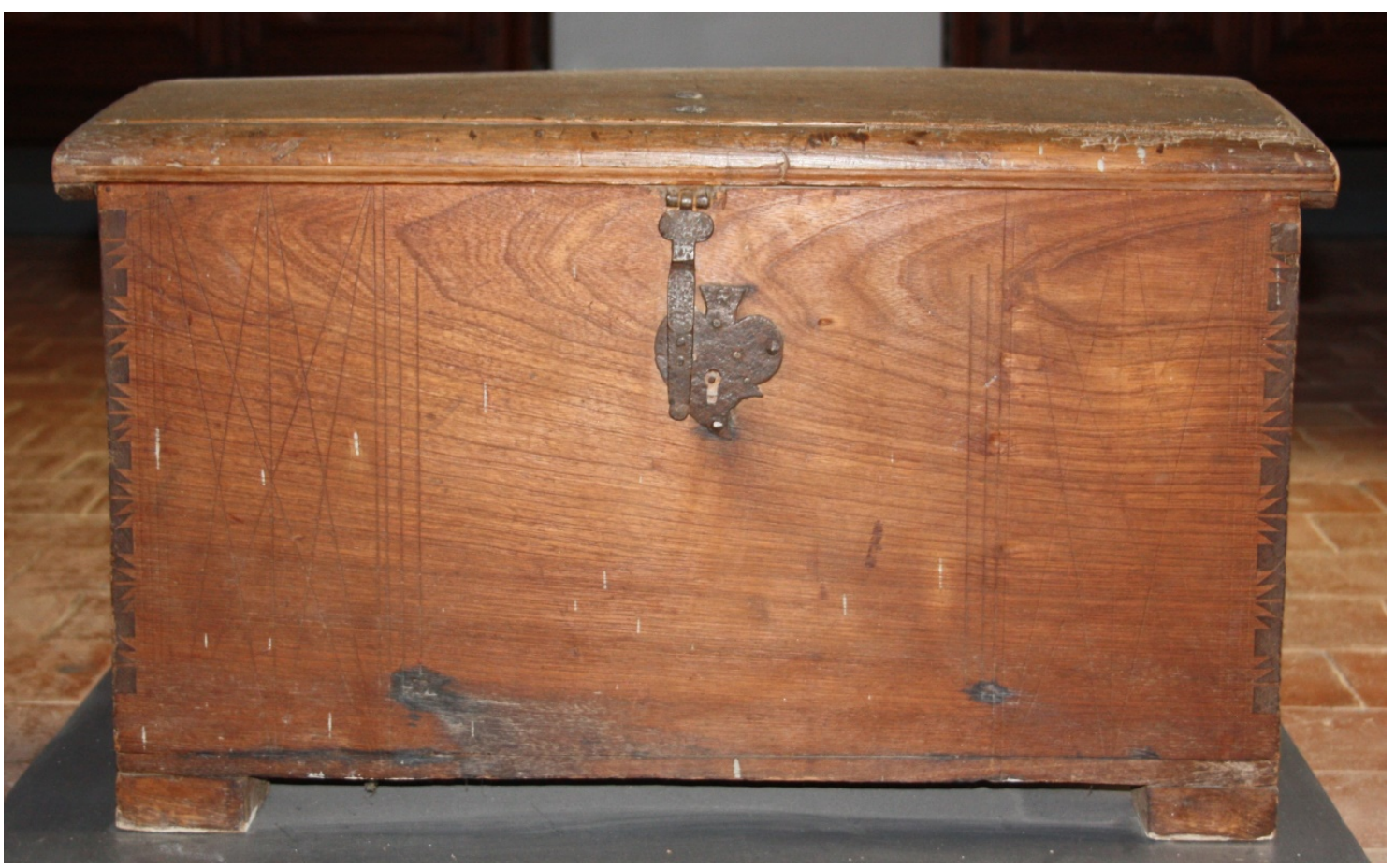

Fig. 2. Arcón de cedro, siglo XVII. Museo de Arte Colonial, Oficina del Historiador de la Habana, fotografía de Rodrigo Ponce, La Habana 2020

En las anteriores referencias, como otras tantas se pueden apreciar la información que refiere a los valores de las piezas, las dimensiones de las mismas; el tiempo de uso, así como de la madera de que estaban hechas y hasta las telas que se utilizaban para forrar el interior. El 12 de febrero de 
1586 se firma un contrato de pago a favor del mercader Diego de Lara, quién había vendido "Seisbaras de rruán de cofre a diez y seis rreales la vara. ${ }^{36} \mathrm{~A}$ pesar de que se destaquen estas características de los cofres, baúles y cajas no ha aparecido, al menos en los documentos que se han consultados, la ubicación que estos tenían dentro de la casa. Algunos podrían sacarse por inferencia, en los dormitorios estarían los que contenían ropa de cama y otros enseres relacionados con este espacio y en las cocinas los que guardaban alimentos.

Como refiere la investigadora Mónica Piera, estudiosa de la sociedad catalana del siglo XVIII, en las familias habaneras del XVI también el arca fue uno de los objetos que se entregaban en las dotes. Mayormente, estos se heredaban por vía materna y constituían, “... un signo del nivel económico de la familia, incluso de su lugar de procedencia, ya que sus características permitían reconocer su lugar de fabricación”. ${ }^{37}$

Las cajas de madera que fueron emplazadas en las salas, además de servir para guardar, o como elemento de decoración se utilizaron como mesas accesorias. Junto con mesitas bajas se les colocaban adornos y bandejas para refrescos y otros objetos. El hecho que el arca tuviera varias funcionalidades, la de guardar y poder colocar objetos encima influyó que se usara por mucho tiempo en las viviendas, a pesar de que se construyesen otros tipos de muebles como cómodas, tocadores y alacenas, entre otros que se utilizaran para guardar.

Los muebles que se emplazaron en las salas de las viviendas habaneras del siglo XVI, dependían del uso que se le daba a este espacio generalmente multifuncional; en ocasiones con variaciones entre el día y la noche. Generalmente se encontraban sillas, mesas y taburetes; y en algunas ocasiones un estrado con cojines y alfombras para sentarse. Las cajas o baúles en estos sitios se colocaban para guardar útiles relacionados con el oficio del dueño de la casa y hasta podían servir de mesas auxiliares. La cantidad y variedad de los muebles de la sala dependieron también del poder adquisitivo del dueño principal y por tanto del tamaño de la casa.

\section{Las alcobas: entre lo íntimo y lo público}

El mueble más importante en las alcobas no podía ser otro que la cama, por su jerarquía y valor se legaba a través de los documentos notariales a los seres queridos y más cercanos. Comprarlos nuevos, significaba un gasto excesivo que no todas las personas podían costear. Los altos precios no se debían a la escasez de las materias primas - La Habana estaba rodeada de bosques maderables - sino a la insuficiencia de carpinteros 38 que se dedicasen a estos trabajos, que en ocasiones no daban abasto con la demanda creciente. De igual manera la importación de este tipo de mobiliario era costosas, por lo que eran utilizados otros tipos de útiles como hamacas y catres.

Camas que se elaboraron por artesanos de la Isla, es la que se mandara a hacer el vecino Gaspar Pérez de Borroto, quien firma un contrato en 1587, con el tornero Marcos González. El artesano debía pagarle por un solar una cifra de dinero y hacerle una cama. 
(...) y más vna cama de madera torneada entera, grande y bien fecha y entablada y acauada de todo punto, con sus aldabas... y la cama se la ha de dar acabada de buena madera y sana, de cahoba, para en todo mes de março del año que verná de mil y quinientos y ochenta e siete años (...). ${ }^{39}$

El uso de camas de aire o hamacas, catres y hasta bancos forrados que se utilizaban para el reposo, se remontan a más de cien años. En escritura que se realizará del 11 de septiembre de 1579 ante el escribano público Juan Pérez de Borroto, el residente en La Habana, Francisco Pabón exigía al también residente, el portugués Andrés Lorenzo que le devolviese entre otras mercaderías, una cama de viento. ${ }^{40} \mathrm{El} 8$ de abril de 1595 , la morena horra ${ }^{41}$ dicta su testamento, en el cual disponía que Heredia, carpintero y soldado que dormía en su casa en una cama de viento nueva y un colchón, le debía la renta de tres meses. ${ }^{42}$ Por su parte, en declaración de la vecina Juana Nuñez de Troya, refiere que en el testamento del sargento Francisco Sanchez, del 15 de septiembre de 1649 se encontraba entre otros bienes una:

(...) espada y daga; un arcabuz que se vendió en 3 pesos una escopeta quebrada; 16 botijas peruleras; una piedra de moler; un pilón con 2 manos 2 tinajas viejas; 2 canoas de lienzo ...camas de viento con los lechos de lienzo crudo una caja cuadrada con cerradura y lleve (...). ${ }^{43}$

Una década después de realizada esta escritura, el vecino Ignacio Fuentes, ${ }^{44}$ al hallarse convaleciente en el hospital San Juan de Dios, enuncia que tenía de su propiedad "Un catre de viento", refiriéndose a unas camas de cuero curtido que asemejaban a un tipo de colchón inflable. Esta última referencia como tantas otras, demuestran primero, que las camas de aire, hamacas y otros tipos de objetos parecidos se utilizaron en La Habana desde las primeras décadas del siglo XVI, y se mantuvieron en uso bien avanzado el siglo XIX; pudiera ser que el clima tropical y húmedo de la isla haya sido uno de los factores que hayan influido en su permanencia.

Segundo, en los primeros dos siglos, no se puede distinguir cuales sectores sociales lo utilizaban más que otros. La presencia de este tipo de objetos en las casas de la urbe habanera fue disminuyendo en la medida que aumentó la producción de camas de madera y su valor fue siendo más asequible. Como tercer resultado, se ha reparado que avanzado el siglo XVIII, el término de cama de aire fue en desuso, no ocurriendo así con el de hamaca. Aunque no es la generalidad, en áreas rurales de la isla de Cuba se emplea la hamaca en sustitución de las camas y otros muebles que realizan esta función.

Además de la cama, las mujeres aportaban al matrimonio colchones, sábanas, almohadas, sobrecamas y otros enseres, entre los que se incluían telas finas con encajes y adornadas con cintas. El ajuar de cama adquirió notable importancia, sobre todo en el momento del casamiento, lo cual marcaba el comienzo de la vida en pareja y la creación de una nueva familia. Es curioso, que en las dotes de las jóvenes casaderas pertenecientes a familias acaudaladas aparecen sábanas, colchones y ropa de vestir de uso, lo contrario que se podría pensar es que por pertenecer a personas con dinero todo sería nuevo.

En escritura sobre recibo de dote, fechada en 1650, el vecino Fredrique de Juan David declaró que, entre los bienes tasados en 1539 pesos, de su 
esposa María Hernández, hija legítima de Pedro Hernández y Marcela Díaz, se incluía el valor de:

(...) una vivienda de casa; colgadizo de tejar; sala, aposentos, con todo el sitio y solar (...)1 colcha de Campeche nueva azúl y blanca con 2 rodapiés en 12 pesos, 2 almohadas con 2 acericos labrados de hilo añil en 12 pesos y mdio; (...) 2 almohadas labradas de hilo acejado con sus acericos en 10 pesos; (...) 2 sábanas nuevas en 16 pesos; sabanas en 8 pesos; 2 tablas de manteles con 12 servilletas en 12 pesos; 1 cama de campo de caoba torneada en 20 pesos; 1 colchón con lana en 12 pesos (...). ${ }^{45}$

Dentro del grupo de mobiliario que se encuentra expuesto en los museos, y que hoy está en desuso se hallan los bargueños. Este mueble se considera dentro del género de los escritorios utilizados por los escribanos, entre otros oficios profesionales en ocasiones se emplazaron en las alcobas (fig. 3). Según la profesora española Margarita Birriel Salcedo, el bargueño es un mueble de origen español característico de los siglos XVI y XVII. Su función era contener papeles, documentos y quizás dinero, por la seguridad que le daba tener cerradura. ${ }^{46}$

Desde los territorios americanos, la Flota importaba disímiles mercancías, entre ellos, artículos de lujo cotizados en La Habana a muy buenos precios. A finales del año de 1649, la señora Francisca Zapata de Ayala, vecina de Valladolid, Yucatán, reclamaba el pago de una mercadería que le debía el comerciante Gaspar Enríquez, avecinado en San Cristóbal de La Habana. Esta se componía entre otros objetos de: "2 bateas grandes de Campeche. Algo hendidas y deslucidas, 11 baulitos de tinteros y salvadera forrados en badana, agentados y diez escusados (...)". ${ }^{47}$

Los tinteros y el papel constituían artículos muy valiosos. Así lo evidencian las constantes reclamaciones por parte del cabildo habanero para que se comercializaran en mayores cantidades. Se disponía que cuando se importasen en la Ciudad no fueran sacados en ningún navío y las personas que los obtuviesen lo notificasen a las autoridades para tener un mayor control de estos. ${ }^{48}$

Relacionados con los tinteros, papel, sellos y secador se hallan los muebles escritorios. De estos, a pesar de no mencionarse con mucha frecuencia en la documentación, se conservan en los museos de la ciudad algunos ejemplares datados de los siglos XVI y XVII; por ejemplo, en el museo de los Capitanes Generales, el de Arte Colonial y en la recién abierta sala expositiva en el Antiguo Convento de Santa Clara, instituciones pertenecientes a la Oficina del Historiador de La Habana, por citar algunos.

Como en el anterior caso, los bufetes, escritorios y bargueños son muebles que pertenecieron a personas con cierto nivel intelectual. Aunque puede resultar peligroso generalizar que solo los individuos de un grupo y no de otros podrían contar con estos muebles, es posible suponer que eran los de mayor nivel adquisitivo quienes los poseían. El vecino Martín Calvo de la Puerta, regidor y personaje ilustre de la ciudad, adquirió el 19 de julio de 1590 una cierta cantidad de mercadería por el valor de 234 reales, entre las que se encontraba: un escritorio pequeño tasado en 120 reales. ${ }^{49} \mathrm{El}$ alto índice de analfabetismo en La Habana de los siglos XVI y XVII hace pensar que eran 
ellos quienes podían sufragarse una mejor educación y por tanto, los que les hallarían utilidad y además podrían costearlos.

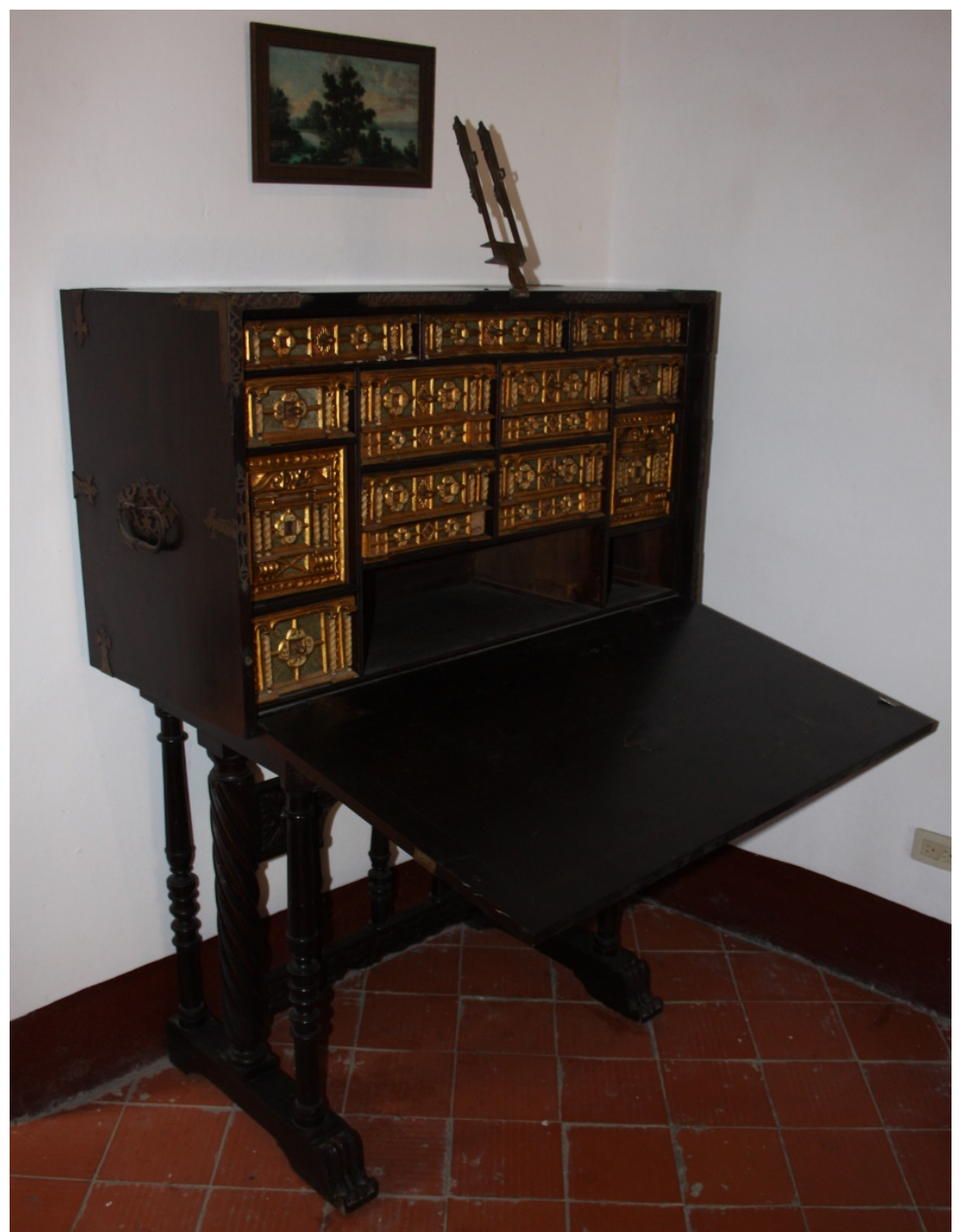

Fig. 3. Bargueño del siglo XVII. Museo de Arte Colonial, Oficina del Historiador de La Habana ${ }^{50}$ Fotografía de Rodrigo Ponce, La Habana 2020

Así mismo es complicado otorgarle carácter de género a este tipo de mobiliario en el período en que se trata, ya que no se cuenta con la información suficiente sobre las características físicas de los mismos, y quienes eran sus dueños. Si bien por las características de segregación de la época eran los hombres los que podían ejercer algún oficio, las mujeres, sobre todo las pertenecientes a los grupos de mayor poder económico, podían recibir algún tipo de enseñanza vinculada con la gramática y las reglas elementales de la aritmética. Es por ello que también ellas pudieron haber utilizado este tipo de mobiliario, el cual se colocaba en sus antecámaras; como sucedió con un escritorio de carey con su mesa, que formó parte de la dote que se entregaría a Catalina de Monsón, esposa del regidor perpetuo Juan Franco, en 1699, el cual fue tasado en cuarenta pesos. ${ }^{51}$ 
En los siglos XVI y XVII, los espacios en una casa se componían, fundamentalmente, de sala, dormitorios, cocina y patio. Las áreas de baño no se habían implementado aún, pues las acciones de higiene y limpieza se desarrollaban dentro de los dormitorios, o se utilizaba una recámara, ubicada como antesala de la alcoba. A estos sitios se transportaban los aguamaniles, las bañeras, las bateas, las grandes palanganas de Campeche, lebrillos y jofainas para el aseo y las evacuaciones corporales. Dedicando no sólo un espacio dentro de la estancia para este tipo de objetos, sino pequeños muebles donde guardarlos.

Los espacios domésticos constituyeron el eje central de la vida de sus habitantes, desde el mismo momento del nacimiento y hasta el final de la vida, en la muerte. En las alcobas era donde se nacía; la señora partera, junto con las mujeres de la familia, ayudaba a llegar al mundo al nuevo miembro. En la alcoba era donde el enfermo era cuidado por sus seres queridos, y desde donde, dado el caso, era trasladado a los pocos hospitales de la Ciudad: el San Felipe, en 1573, que cambió su nombre por el de San Juan en 1633; el de San Francisco de Paula, en 1655, clausurado en 1688; y el de Belén, en 1704.52 Lo más común era que las personas muriesen en sus casas y que desde estas fueran trasladadas a las iglesias donde eran enterradas. El ciclo de la vida, nacimiento y muerte, actos que ocurrieron en las alcobas y que acrecientan el misticismo de estos espacios.

\section{Reflexiones finales}

La multiplicidad y variedad de los espacios públicos en las sociedades actuales (hospitales, cines, teatros, parques, comercios, oficinas y otros), ha llevado a que la casa sea vista únicamente como hogar; sin embargo, no siempre fue de esta manera. En los siglos XVI y XVII, en el recién fundado San Cristóbal de La Habana, confluyeron variadas actividades en las viviendas, y como consecuencia las estancias que las conformaban fueron variando según el uso y las prácticas cotidianas de los dueños.

$\mathrm{Al}$ analizar los testamentos y las dotes, entre otros documentos notariales inscritos en el transcurso de los primeros siglos coloniales, se ha podido constatar que en lo que respecta a los muebles, no variaron de forma significativa y los cambios fueron más en la calidad de la hechura de estos que en la variedad; una de las causas de la simplicidad del mobiliario doméstico sin duda era los altos precios de estos. Por una parte, la importación era costosa y por otro lado, a pesar de que en la Isla existían las materias primas suficientes para su elaboración, el número de artesanos era muy bajo con respecto a la creciente demanda. El desarrollo de la urbe habanera como ciudad portuaria trajo como consecuencia que, carpinteros de ribera, carpinteros, herreros, entre otros practicantes de oficios, se asentaran de forma definitiva en la ciudad. En los talleres, aprendices y maestros realizaban copias de muebles europeos, pero al mismo tiempo comenzaron a crear un estilo más autóctono, donde se realzaban las maderas cubanas con proporciones audaces y una rica ornamentación. 


\title{
NOTAS
}

\author{
${ }^{1}$ Denominaron puerto de Carenas, por haber carenado en él Sebastián de Ocampo, en el año de 1508, \\ cuando realizaba el bojeo a la isla de Cuba \\ ${ }^{2}$ Anita Arroyo, Las artes industriales en Cuba. Su historia y evolución desde las culturas precolombinas \\ hasta nuestros días (La Habana: Cultural, S. A., 1943). \\ ${ }^{3}$ Emilio Roig, La Habana. Apuntes históricos (La Habana: Editora del Consejo Nacional de Cultura, \\ Segunda Edición, 1963) Tomo I \\ ${ }^{4}$ Leví Marrero, Cuba: Economía y Sociedad. Siglo XVI: la economía (Madrid: Editorial PLAYOR, S.A., \\ Segunda reimpresión 1993) Tomo II \\ ${ }^{5}$ Lilia Martín Brito, "El mueble de los siglos XVI y XVII en Cuba," Res Mobilis. Revista internacional de \\ investigación en mobiliario $y$ objetos decorativos, 6 (2016), 56-75,
} https://www.unioviedo.es/reunidi/index.php/RM/issue/view/881

${ }^{6}$ En el contexto habanero de los siglos XVI y XVII, la mayoría de los muebles no tenían un sello de autor; pero se conoce el nombre de los artesanos que trabajaron en el oficio por algún contrato u otro documento notarial que los relacionaba. En la Habana, las primeras asociaciones de artesanos fueron las cofradías. Las devociones católicas fueron capaces de promover o facilitar la asociación en cofradías de acuerdo a la diversidad étnica, cultural y según el trabajo que ejercía la población habanera. A finales del siglo XVI existían las cofradías de San Crispín y San Cipriano o de los zapateros, la de los sastres, la de San Lorenzo formado por herreros, y la de San José por los carpinteros. Véase a Carlos Venegas, Ciudad del Nuevo Mundo (La Habana: Instituto Cubano de Investigación Cultural Juan Marinello, 2012) 180.

${ }^{7}$ María del Pilar López, "El espacio privado, de lo público a lo íntimo: alcobas, estrados, oratorios, estudios y cocinas en Santafé de Bogotá, siglos XVII y XVIII," en Las Casas en la Edad Moderna, ed. Margarita Birriel Salcedo (Zaragoza: Institución Fernando el Católico, 2017), 291-340

${ }^{8}$ Madeline Menéndez, La casa habanera. Tipología de la arquitectura doméstica en el centro histórico (La Habana: Boloña, 2007)

${ }^{9}$ Rosalía Oliva, "Allende los mares. Primeras casas de españoles en La Habana del siglo XVI", en De puertas para adentro. La casa en los siglos XV-XVI, ed. María Elena Díez Jorge (Granada: Comares, 2019), $101-116$

${ }^{10}$ En las salas se realizaron bautizos, tertulias y hasta representaciones teatrales, teniendo en cuenta que en La Habana no hubo teatro hasta mediados del siglo XVIII. Incluso en las casas de los regidores del Cabildo habanero sesionaron algunas de sus reuniones. Véase: Archivo Histórico de la Ciudad (AHC), Oficina del Historiador de La Habana, Actas capitulares de La Habana trasuntadas, tomo I

${ }^{11}$ Rosalía Oliva Suárez, "Los espacios domésticos habaneros: 1650-1750" (Tesis Doctoral, Universidad de Granada, 2014)

${ }^{12}$ Emilio Roig, La Habana. Apuntes históricos (La Habana: Editora del Consejo Nacional de Cultura, Segunda Edición, 1963) Tomo I, 86

${ }^{13}$ Los resultados expuestos en este artículo forman parte de un trabajo más amplio sobre el mobiliario en los espacios domésticos habaneros del siglo XVI. Investigación I+D "Vestir la casa: espacios, objetos y emociones en los siglos XV y XVI (VESCASEM)". PGC2018-093835-B-100, financiado por FEDER/Ministerio de Ciencia e Innovación-Agencia Estatal de Investigación. Dirigida por la Dra. Elena Diez Jorge. Ver: http://vescasem.ugr.es/es/index.html

${ }^{14}$ Archivo Histórico de la Ciudad (AHC) Actas del Cabildo Trasuntadas, Oficina del Historiador de La Habana, Tomo 1, folio 233v, reunión del 24 de abril de 1556

${ }^{15}$ Irene Wright, Historia documentada de San Cristóbal de La Habana (La Habana: Imprenta El Siglo, 1927), Tomo I, pág. 35

${ }^{16}$ En los documentos del siglo XVI fechados en La Habana, aparecen los términos de sillón y silla de brazo indistintamente, refiriéndose a lo que se le denominó a partir de la segunda mitad del siglo XIX sillón frailero. El cual se describe como un asiento con respaldo y brazos rígidos, que favorecen una postura solemne. El origen de su nombre se debe a su amplia presencia en los conventos, y fue uno de los elementos característicos del mobiliario español de los siglos XVI y XVII. El 'seggiolone' o silla de brazos italiana 
solía estar tapizado con relleno o acolchado, mientras que el modelo español, usado en Cuba se caracterizaba, en general, por su asiento y respaldo de cuero al aire con clavazón.

Tomado de: https://www.facebook.com/museonacionaldelprado/posts/10155789256978363/

${ }^{17}$ Cecilia Edith Moreyra, "Vida cotidiana y entorno material. El mobiliario doméstico en la ciudad de Córdoba a fines del siglo XVIII," Revista Historia Críca (Bogotá, Universidad de los Andes, mayo-agosto 2009),122-144

${ }^{18}$ Archivo de la República de Cuba (ARNAC), Protocolo, Escribanía de Regueyra. Protocolo de Martín Calvo de la Puerta 1584-1585. Tomo II, folio 58v-60v

${ }^{19}$ ARNAC, Protocolo, Escribanía de Regueyra, Tomo I, f 393v

${ }^{20}$ ARNAC, Protocolo, Escribanía de Regueyra, Tomo I, f 76-80

${ }^{21}$ ARNAC, Protocolo, Escribanía de Regueyra, año 1687-1690, f 5

${ }^{22}$ María Luisa Lobo Montalvo: Havana: History and Architecture of a Romantic City. The Monacelli Press, Inc., 2000, p. 45. Citado por: Michael Connors, "Entorno al Mueble Colonial Cubano," Revista OPUS Habana, Volumen IV, No 3, año 2002, OHC, 29.

${ }^{23}$ Gloria Franco, "La vivienda en la España ilustrada: habitabilidad, domesticidad y sociabilidad," en $E l$ mundo urbano en el siglo de la Ilustración, ed. Ofelia Rey Castelao y Roberto Javier Lòpez Lòpez (Santaigo: Xunta de Galicia, 2009) Tomo II, 125

${ }^{24}$ ARNAC, Protocolo, Escribanía de Regueyra, año 1687-1690, f 825

${ }^{25}$ Marta Pérez Toral, "Tejidos y textiles en la vida cotidiana del siglo XVII," en Revista de Investigación Lingüística (Murcia, Universidad de Murcia, No. 20, 2017),195-219

${ }^{26}$ ARNAC, Protocolo, Escribanía de Regueyra, año 1590, Tomo 2, folios 1 al 147

${ }^{27}$ Anita Arroyo, ob.cit, p. 158

${ }^{28}$ Cecilia Edith Moreyra. Ob.cit., p 140

${ }^{29}$ María Teresa Rojas, Índice y extracto del archivo de protocolos de La Habana (1578-1585) (La Habana: Imprenta Úcar, García y Cía, 1947),197-198. Protocolo de Juan Pérez de Borroto 1578-1579. Agosto 18, I, folio $1008 \mathrm{r}-1011 \mathrm{r}$

${ }^{30}$ ARNAC, Protocolo, Escribanía de Regueyra, año 1690, f 8

${ }^{31}$ ARNAC, Protocolo, Escribanía de Regueyra, año 1699, f 154-174

${ }^{32}$ Margarita María Birriel; Carmen Hernández, Devociones domésticas: objetos devocionales en los hogares rurales (Siglo XVIII). Esta investigación ha sido sufragada por el Ministerio de Economía e Innovación mediante el proyecto: HAR2013-48901-C6-6-R. Familia, desigualdad social y cambio generacional en España centro meridional, 1700-1900

${ }^{33}$ Leví Marrero, Ob.cit. p 456, fuente: AGI, Santo Domingo, 129

${ }^{34}$ ARNAC, Protocolo, Escribanía de Regueyra, año 1687-1690, f 5

${ }^{35}$ ARNAC, Protocolo, Escribanía de Regueyra, año 1650, f 565v

${ }^{36}$ María Teresa Rojas, Ob.cit. Tomo II, pág 262, 1587, febrero 12, tomo II, folio 244r-245 r

${ }^{37}$ Mónica Piera Miquel "La cómoda y el tocador, muebles de prestigio en la sociedad catalana del siglo XVIII," consultado en: file:///C:/Users/ARQUEO 1/AppData/Local/Temp/DialnetLaComodaYElTocadorMueblesDePrestigioEnLaSociedadCa-2378077.pdf p. 261

${ }^{38}$ Rosalía Oliva, "La población habanera en la segunda mitad del siglo XVII, los oficios," Boletín del Archivo Nacional de la República de Cuba, 21 (2013), 136-145

${ }^{39}$ María Teresa Rojas, Ob.cit, tomo II, pág 159, 1586, agosto 5, III, folio 505v.-507v

${ }^{40}$ María Teresa Rojas, Ob.cit, tomo I. págs 224-225. Protocolo de Juan Pérez de Borroto 1578-1579.

${ }^{41}$ Mujer negra que fue esclava y logró su libertad

${ }^{42}$ ARNAC, Protocolo, Escribanía de Regueyra, año 1595, del No. 1 al 147. Consta de seis partes. Síntesis del tomo. 1 parte. Fondo No. 509. (8 de enero hasta 15 de noviembre). Escritura otorgada por Juan Baptista Guilisasti

${ }^{43}$ ARNAC, Protocolo, Escribanía de Regueyra, año 1690, Tomo I, folio 291v

${ }^{44}$ ARNAC, Protocolo, Escribanía de Regueyra, año 1659, f 54-58

${ }^{45}$ ARNAC, Protocolo, Escribanía de Regueyra, año 1650, f 504

${ }^{46}$ Margarita María Birriel, "El mueble en Granada. Pinos del Valle en el siglo XVIII," en Vida cotidiana en la España de la Ilustración, ed. Inmaculada Saavedra (Granada: Editorial Universidad de Granada, 2012), 159-186 
${ }^{47}$ ARNAC, Protocolo, Escribanía de Regueyra, año 1650, t1, f 272

${ }^{48}$ AHC, Actas del Cabildo Trasuntadas, Oficina del Historiador de La Habana, año 1655: Tomo 12, f 105v ${ }^{49}$ ARNAC, Protocolo, Escribanía de Regueyra, 1590, del No. 1 al 147. Consta de tres partes. Síntesis del tomo. 1 parte. Estas escrituras fueron autorizadas por Juan Pérez Borroto

${ }^{50}$ Bargueño expuesto en el Museo de Arte Colonial, de la Oficina del Historiador de La Habana. Bargueño de madera, marfil, metal y tela. La parte superior con tapa trabajada con aplicaciones de metal en forma de rombos y cerradura en forma de escudo. Tiene tres conchas pequeñas a cada lado. A los laterales tiene asas de hierro. En su interior, doce gavetas y dos compartimientos con cerraduras, trabajadas en marfil y dorado. La parte interior, patas con tres columnas, las del medio salomónicas, que se unen a una pieza central tallada rematada con cuatro perillas. Fue trabajado en el interior del cajón con marfil y se hallaron herrajes en la parte delantera y lateral.

${ }^{51}$ ARNAC, Protocolo, Escribanía de Fornarys, año 1699, f 188

${ }^{52}$ Emilio Roig. La Habana. Apuntes históricos (La Habana: Editora del Consejo Nacional de Cultura, Segunda Edición, 1964) Tomo III, 71-76

Fecha de recepción: 19 de junio de 2020

Fecha de revisión: 21 de junio de 2020

Fecha de aceptación: 4 de septiembre de 2020 